\title{
Down Syndrome: A Review for the Dental Professionals
}

\author{
Dr. Mohammed S Aldossary* \\ *(BDS, MClinDent. Specialist in Pediatric Dentistry, Ministry of Health, Riyadh, Saudi Arabia) \\ *Corresponding author: Dr. Mohammed S Aldossary*
}

\begin{abstract}
This article is aimed to provide general and pediatric dentists with the essential knowledge to provide care to children with Down syndrome. The features of Down syndrome, the medical and dental issues which may be present in a child with Down syndrome, and how might these may impact on dental care, will be presented in this article.
\end{abstract}

Keywords: Dental care, Down syndrome, Trisomy 21

\section{Introduction}

Down syndrome (DS) is a congenital genetic "chromosomal" disorder caused by an error in cell division that results in the presence of an additional third chromosome 21; a triplication of material on chromosome 21. It has also been known as mongolism or Trisomy 21, and it was first described by John Langdon Down, the physician who identified the syndrome in 1866.[1,2]

The etiology is unknown, however, three genetic variations can cause DS. In 95\%, DS is caused by an extra chromosome 21 in all cells (trisomy 21) giving them 47 chromosome instead of the normal 46, i.e. three copies of chromosome 21 in every cell in the body. In 3\%, material from one chromosome 21 is translocated onto another chromosome (translocation trisomy 21 ). In $2 \%$, is due to mosaic trisomy 21 , when the extra chromosome 21 is present only in some cells (mosaicism), i.e. some cells have 46 chromosomes and other cells have 47.[1,2]

The world overall prevalence is 1 in 800-1000 live births. The prevalence depends on the illegality of abortion in different countries. Incidence increases with increasing maternal age from 35 to $40+$ years old. [3]

Prenatal diagnosis is possible via amniocentesis, chorionic villus sampling, or percutaneous umbilical blood sampling. Because these tests are invasive, an individualized risk assessment based on maternal age, maternal serum markers (e.g., serum alpha-fetoprotein), and fetal physical markers (e.g., nuchal translucency on ultrasonography) may be done to determine elevated risk and the need for further testing. If not diagnosed prenatally, DS is usually suspected and diagnosed at birth, based on clinical features and cytogenetic studies, respectively.[1,2]

Multidisciplinary treatment depends on the type and level of disability, and commonly involves a team of clinician specialists in cardiology, ophthalmology, orthopedics, neurology, audiology, physical and occupational therapy, speech-language therapy, nutrition, and mental health.[4]

Although the life expectancy for people with DS has increased substantially to age 50 and beyond, about one-third of infants with DS die in the first few years of life from cardiac disease. The infectious diseases, particularly from pneumonia and hematological malignancies may also influence the prognosis and reduce life expectancy.[5]

\section{Clinical Presentation and Characteristic Features}

Learning disability (100\%), is the most frequent genetic cause of mild to moderate learning disability. The most common features among DS patients include short stature, brachycephaly (small head), rounded small face, mid-face hypoplasia with a flat nasal bridge, upward slant of the eyes (slanted palpebral fissures) and epicanthal folds. In addition, the following features are common:[4,5]

- Muscular hypotonia, increased joint flexibility, clinodactyly (short fifth finger), and wide space in-between the $1^{\text {st }}$ and $2^{\text {nd }}$ toe (sandal gap).

- Small mouth, small ears, excessive skin at the nape of the neck, short neck, obesity and delays in speech and language development.

- Simian (single) palmar creases, i.e. the hands of children with DS are stubby with a pronounced transverse palmar crease.

- Brushfield's spots in the iris, nasal septum deviation, and small inter-nipple distance.

\section{Medical manifestations}

Down syndrome affects almost every organ system and can cause a number of cognitive and physical impairments. These problems are presented and categorized as follow:[1,2,4,5] 


\subsection{Neurological and behavioral alterations:}

- Neuropsychiatric diseases: Learning disability with wide range of behavior, dementia, memory loss, progressive loss of skills, which impact on personal oral care, and epilepsy.

- Psychiatric conditions: Autism, depression, attention deficit hyperactivity disorder (ADHD) and obsessive compulsive disorder.

- Premature aging: Alzheimer's type changes in brain and risk of stroke (over the age of 40 years), skin wrinkling, early greying and loss of hair.

\subsection{Endocrine:}

- Hypothyroidism: About 30\% of patients and present with facial features like thick lips, puffy eyelids, sad expression, dry hair, and dry/cold skin.

- Diabetes mellitus: Increased incidence has been reported in patients with DS who are between the ages of 24 and 34 years.[6]

\subsection{Sensory deficits:}

- Hearing loss: About $75-90 \%$ in at least one ear. Short Eustachian tubes, chronic media otitis with effusion and conductive hearing loss, which interferes with their language acquisition are some of the ear-associated complications.[7]

- Visual defects: Blindness is affecting about $8 \%$, and cataracts occur in approximately $3 \%$ of children with DS but can be surgically removed.

\subsection{Esophageal (Gastric) dysfunctions:}

- Gastroesophageal reflux and vomiting are frequent findings in DS.

- Coeliac disease is a finding in 5-7\% of DS patients.[8]

\subsection{Respiratory abnormalities:}

- Respiratory tract infections: Due to abnormal airway anatomy, hypotonia, aspiration of oral secretions and bacteria with immunological alterations. Most common respiratory infections are pneumonia, rhinopharyngitis and bronchitis.[7]

- Obstructive sleep apnea increased because of the relative macroglossia and enlarged adenoids and tonsils may exacerbate this issue.[9]

\subsection{Cardiovascular abnormalities:}

Fifty percent of DS patients have cardiac disorders associated with early onset of pulmonary hypertension. Congenital heart disease (CHD) is common and the most common defects are: Atrioventricular septal defect (39\%), atrial septal defect (29-42\%), patent ductus arteriosus (17\%), ventricular septal defect (14$43 \%)$ and tetralogy of Fallot (6\%). CHD is the primary cause of early mortality in patients with DS.[10,11]

\subsection{Musculoskeletal abnormalities:}

- Spinal problems: Atlantoaxial instability (i.e. congenital increased hyperflexibility of the transverse ligaments of the cervical vertebrae affecting the two bones at the top of the spinal cord $\mathrm{C} 1$ and $\mathrm{C} 2$ ) can cause spinal cord compression if the neck is not handled considerately. Also, increased susceptibility to transient myelodysplasia or defective development of the spinal cord.[7]

- Generalized Muscle hypotonia.

\subsection{Hematological abnormalities:}

DS patients are 10-15 times more likely than others to develop leukemia (myeloid type), acute lymphoblastic leukemia, with increased risk in children younger than 5 years. Also, transient neonatal leukemia known as transient abnormal myelopoiesis (10\%) and iron deficiency (10\%).

\subsection{Immunological abnormalities:}

Multiple immunological defects (IgA and T lymphocyte function defects) may lead to skin infection (atopic dermatitis), chronic upper respiratory tract infections, pneumonia, gastrointestinal tract infections and infective hepatitis B virus infection.

\subsection{Sexual development:}

Onset of puberty is similar to that of other adolescents. Females with DS are able to have children but males often have a diminished capacity to reproduce (sterile) because of underdeveloped genitalia.[12] 


\section{Dental Manifestations}

- Open mouth posture with a protrusive tongue. The tongue may be absolutely or relatively large; macroglossia, and is often with deep fissures that can trap food causing halitosis.[13] Tongue increased pressure against the teeth and may result in a scalloped appearance.

- Drooling is not related to hypersalivation but rather to combination of an open mouth posture, a protruding tongue and hypotonic orofacial musculature.[14]

- Lips are usually thick, dry and fissured with a poor anterior oral seal. Mouth breathing because of narrow and sometimes occluded nasal passages worsened by frequent upper respiratory tract infections, may lead to a dry mouth.[15]

- The maxilla is small, the mandible is protruded, and class III malocclusion is common.[16] Also, spaced malocclusion with anterior open bite and posterior cross bite.[17]

- Hypotonicity of perioral muscles, lips and tongue may result in problems with sucking swallowing, increased drooling and angular chilitis. Positive effect of the stimulating plate on facial appearance and orofacial function leading to improved speech, swallowing and masticatory function.[18]

- Oral complications and signs of leukemia, include symptoms of anemia, increased bleeding tendency, gingival bleeding, persistent lesions and increased susceptibility to infection. The most common symptom induced by anti-leukemia treatment is mucosal pallor.[19]

- Oral manifestation of coeliac disease: glossitis, angular stomatitis and oral aphthae.[20]

- The palate often appears to be short, high vaulted and narrow. Additionally, increase incidence of bifid uvula, cleft lip and cleft palate.[13]

- Delayed tooth formation and eruption, can be 2-3 years behind a child's normal eruption pattern. The primary dentition may begin to appear only after 9 months and may take 5 years to complete with delay in exfoliation and affected sequence of eruption.[21]

- Hypodontia; congenitally missing teeth, and high incidence of impacted cuspids and bicuspids.[13,22]

- Morphological abnormalities include peg lateral incisors, taurodonts, hypoplastic, microdontia, short, small conical crowns and roots. Unfavorable crown to root ratio may increase tooth mobility and lead to early tooth loss.[22,23]

- Periodontal diseases are more severe in children with DS and they are susceptible to a more generalized aggressive form of periodontitis.[24] This can result in bone loss and deep gingival pocketing. If not treated, the disease will result in tooth loss and lower central incisors are more affected and lost. Local risk factors include poor oral hygiene with increased plaque retention in malocclusion. Also, anterior open bite, open mouth and lack of an anterior lip seal.[25] General risk factors include immunodeficiency (leukocyte defects and impaired phagocyte function in neutrophils and monocytes). Additionally, Acute Necrotizing Ulcerative Gingivitis is another form of periodontal diseases that seen more often in individuals with DS.[26]

- Dental Caries: Opinion is divided on whether DS is a determinant of a higher or a lower caries risk or if there is no difference in risk compared with the general population. Some reports concluded that DS population are with higher caries prevalence, $[27,28]$ while others concluded that there is no difference in caries prevalence compared to healthy groups.[29-33] However, most investigators have found a lower prevalence of caries in DS patients in both dentitions.[34-38] This low caries incidence in children with DS is in spite of the presence of increased risk factors for caries such as cariogenic diet, decreased salivary flow rate,[34,39,40] mouth breathing, imbalanced occlusal forces and poor access to oral hygiene.[37] Caries risk assessment is likely to be obtained by evaluation factors such as a high sugar or acidic diet, frequency of snacking, low social status, appropriate oral health and past dental history.[37] The precise cause of the lower caries prevalence is still unclear. The proposed reasons are as follow:

a) Dental anomalies: Delayed eruption, microdontia and spaced teeth due to hypodontia will reduce caries risk.[41] However if there are other risk factors as an increased sugar consumption, poor oral hygiene mouth breathing dry mouth , risk may be equivalent to or higher than that of other children.

b) Salivary $\mathrm{pH}$ and buffering capacity: Conflicting results as some studies showed higher values, while others showed no difference, and others showed lower values.[34,37,38,40]

c) High salivary IgA concentration "immune protection", and high salivary bicarbonate and minerals.[37]

d) Associated with the parent's greater concern about oral health care in DS.[38]

e) The mechanism of remineralization process may be different and Magnesium may be one of the factors affecting enamel remineralization.[42]

- Tooth wear, attrition due to bruxism, and erosion due to gastric reflux and vomiting are more frequent among DS patients. Whilst bruxism has been reported as more common in children with DS,[7] the findings are controversy as bruxism has been reported as no more common in children with DS than in those without it.[14,43] 


\section{Dental Management}

- Risk assessment: In general, it is mandatory to check patient's medical and dental history and to do comprehensive assessment. Infection control and aggressive elimination of any dental infection are important. Also, assessment regarding drug using for cardiac defect (e.g. platelet aggregation inhibitors) and make sure that the patient receives proper medical care. Consultation with the patient's health care provider is recommended prior to commencing dental treatment. The antibiotic prophylaxis against infective endocarditis is not recommended for people undergoing dental procedures.[44-46]

- Cooperation: Children with DS have learning disability but exhibit a wide range of behavior in the dental setting, including cooperation, compliance, mild to moderate anxiety, phobia and complete lack of cooperation. For many patients, it is possible to carry out simple restorative treatment and preventive measures using standard behavioral management techniques such as tell-show-do, positive reinforcement, modelling, distraction and both verbal and nonverbal communication. Also, it is recommended to keep the appointment short and focusing on a specific treatment.[41,45,46]

- Parents and caregivers oral health education: Motor functions are usually delayed in younger persons with DS, but coordination improves with age. Therefore, good oral hygiene may need to be responsibility of the primary caregiver until the individual can develop the necessary coordination to become selfsufficient.[47]

- Local Anesthesia: Most of DS patients can be treated under local anesthesia with aware of patient positioning to avoid neck hyperextension.[45]

- Conscious sedation: Can be very useful to reduce anxiety, although careful assessment of respiratory function and infection is important. There may be complications of airway management due to short neck, large tongue obstructed nasal passage and sleep apnea.[4]

- General anesthesia: This is to be at hospital by a specialist. Difficulties include cardiac defect, respiratory disease, difficulty in intubation, anemia, atlantoaxial (care during manipulation of the patient's neck and precaution to avoid hyperextension and direct pressure on the neck during intubation and extubation) and hepatitis B carriage.[7]

- Preventive approach: It is recommended to do professional cleaning, diet counselling, oral hygiene and motivation. Additionally, to ensure that medications given are sugar free. For the prevention of periodontal disease, it is recommended to control plaque and use a tooth paste containing Triclosan with either a copolymer or zinc citrate chlorhexidine mouthwash.[47] Frequent and regular recalls and maintenance visits are mandatory.

- Patients with bronchitis or asthma, the bronchodilating inhalers are recommended to be available.[5]

- Dental treatment modification:

a) Assessment of the periodontal status; periodontal treatment is a priority.

b) Orthodontic consultation: the prognosis is often poor because of learning disability, parafunctional habits and severe periodontal disease. However, an early palatal widening with removable appliance may be useful in selected patients. Also, removable orofacial stimulation plates (e.g. Castillo-Morales) have been recommended in young children to improve orofacial muscular tone and tongue position.[7,18]

\section{References}

[1]. Bull MJ, Committee on Genetics. Health Supervision for Children With Down Syndrome. Pediatrics, 128(2), 2011, 393-406.

[2]. Weijerman ME, De Winter JP. Clinical practice: The care of children with Down syndrome. Eur J Pediatr, 169(12), 2010, 1445-1452.

[3]. Parker SE, Mai CT, Canfield MA, et al. Updated national birth prevalence estimates for selected birth defects in the United States, 2004-2006. Birth Defects Res Part A - Clin Mol Teratol, 88(12), 2010, 1008-1016.

[4]. Boyd D, Quick A, Murray C. The Down syndrome patient in dental practice, Part II: clinical considerations. N Z Dent J, 100(1), 2004, 4-9.

[5]. Abanto J, Ciamponi AL, Francischini E, Murakami C, de Rezende NPM, Gallottini M. Medical problems and oral care of patients with Down syndrome: a literature review. Spec Care Dent, 31(6), 2011, 197-203.

[6]. Anwar AJ, Walker JD, Frier BM. Type 1 diabetes mellitus and Down's syndrome: prevalence, management and diabetic complications. Diabet Med, 15(2), 1998, 160-163. 
[7]. Macho V, Coelho A, Areias C, Macedo P, Andrade D. Craniofacial features and specific oral characteristics of Down syndrome children. Oral Health Dent Manag, 13(2), 2014, 408-411.

[8]. Holmes G. Gastrointestinal disorders in Down syndrome. Gastroenterol Hepatol from bed to bench, 7(1), 2014, 6-8.

[9]. Sato K, Shirakawa T, Niikuni N, Sakata H, Asanuma S. Effects of oral care in Down syndrome children with obstructive sleep apnea. J Oral Sci, 52(1), 2010, 145-147.

[10]. Freeman SB, Bean LH, Allen EG, et al. Ethnicity, sex, and the incidence of congenital heart defects: a report from the National Down Syndrome Project. Genet Med, 10(3), 2008, 173-180.

[11]. Jaiyesimi O, Baichoo V. Cardiovascular malformations in Omani Arab children with Down's syndrome. Cardiol Young, 17(2), 2007, 166-171.

[12]. Roizen NJ, Patterson D. Down's syndrome. Lancet (London, England), 361(9365), 2003, 1281-1289.

[13]. Shore S, Lightfoot T, Ansell P. Oral disease in children with Down syndrome: causes and prevention. Community Pract, 83(2), 2010, 18-21.

[14]. López-Pérez R, Borges-Yáñez SA, López-Morales P. Anterior open bite and speech disorders in children with Down syndrome. Angle Orthod, 78(2), 2008, 221-227.

[15]. Mouradian WE. The face of a child: children's oral health and dental education. J Dent Educ, 65(9), 2001, 821-831.

[16]. Bauer D, Evans CA, Begole EA, Salzmann L. Severity of occlusal disharmonies in down syndrome. Int J Dent, 2012, 2012, 872367.

[17]. Oliveira AC, Pordeus IA, Torres CS, Martins MT, Paiva SM. Feeding and nonnutritive sucking habits and prevalence of open bite and crossbite in children/adolescents with Down syndrome. Angle Orthod, 80(4), 2010, 748-753.

[18]. Limbrock GJ, Castillo-Morales R, Hoyer H, Stöver B, Onufer CN. The Castillo-Morales approach to orofacial pathology in Down syndrome. Int J Orofacial Myology, 19(1), 1993, 30-37.

[19]. Maloney KW, Taub JW, Ravindranath Y, Roberts I, Vyas P. Down Syndrome Preleukemia and Leukemia. Pediatr Clin North Am, 62(1), 2015, 121-137.

[20]. Mazurek D, Wyka J. Down syndrome--genetic and nutritional aspects of accompanying disorders. Rocz Panstw Zakl Hig, 66(3), 2015, 189-194.

[21]. Montserrat Diéguez-Pérez, de Nova-García MJ, Mourelle-Martínez MR, Bartolomé-Villar B. Oral health in children with physical (Cerebral Palsy) and intellectual (Down Syndrome) disabilities: Systematic review I. J Clin Exp Dent, 8(3), 2016, e337-e343.

[22]. de Moraes MEL, de Moraes LC, Dotto GN, Dotto PP, dos Santos LR de A. Dental anomalies in patients with Down syndrome. Braz Dent J, 18(4), 2007, 346-350.

[23]. Mayoral-Trias MA, Llopis-Perez J, Puigdollers Pérez A. Comparative study of dental anomalies assessed with panoramic radiographs of Down syndrome and non-Down syndrome patients. Eur J Paediatr Dent, 17(1), 2016, 6569.

[24]. AlSarheed MA. Comparative study of oral health among trisomy 21 children living in Riyadh, Saudi Arabia: Part 2, gingival condition. Saudi Dent J, 27(4), 2015, 224-227.

[25]. Frydman A, Nowzari H. Down syndrome-associated periodontitis: a critical review of the literature. Compend Contin Educ Dent, 33(5), 2012, 356-361.

[26]. Morgan J. Why is periodontal disease more prevalent and more severe in people with Down syndrome? Spec Care Dentist, 27(5), 2007, 196-201.

[27]. Oredugba FA. Oral health condition and treatment needs of a group of Nigerian individuals with Down syndrome. Down's Syndr Res Pract, 12(1), 2007, 72-76.

[28]. Shyama M, Al-Mutawa SA, Morris RE, Sugathan T, Honkala E. Dental caries experience of disabled children and young adults in Kuwait. Community Dent Health, 18(3), 2001, 181-186.

[29]. Fung K, Allison PJ. A comparison of caries rates in non-institutionalized individuals with and without down syndrome. Spec Care Dent, 25(6), 2005, 302-310.

[30]. Mathias MF, Simionato MR, Guaré RO. Some factors associated with dental caries in the primary dentition of children with Down syndrome. Eur J Paediatr Dent, 12(1), 2011, 37-42.

[31]. AlSarheed M. A comparative study of oral health amongst trisomy 21 children living in Riyadh, Saudi Arabia: Part 1 caries, malocclusion, trauma. Saudi Dent J, 27(4), 2015, 220-223.

[32]. Ivancić Jokić N, Majstorović M, Bakarcić D, Katalinić A, Szirovicza L. Dental caries in disabled children. Coll Antropol, 31(1), 2007, 321-324.

[33]. Moreira MJS, Schwertner C, Jardim JJ, Hashizume LN. Dental caries in individuals with Down syndrome: a systematic review. Int J Paediatr Dent, 26(1), 2016, 3-12.

[34]. Lee SR, Kwon HK, Song KB, Choi YH. Dental caries and salivary immunoglobulin A in Down syndrome children. J Paediatr Child Health, 40(9-10), 2004, 530-533.

[35]. Deps TD, Angelo GL, Martins CC, Paiva SM, Pordeus IA, Borges-Oliveira AC. Association between Dental Caries and Down Syndrome: A Systematic Review and Meta-Analysis. PLoS One, 10(6), 2015, e0127484: 1-11.

[36]. Areias CM, Sampaio-Maia B, Guimaraes H, Melo P, Andrade D. Caries in Portuguese children with Down syndrome. Clinics (Sao Paulo), 66(7), 2011, 1183-1186.

[37]. Cogulu D, Sabah E, Kutukculer N, Ozkinay F. Evaluation of the relationship between caries indices and salivary secretory IgA, salivary $\mathrm{pH}$, buffering capacity and flow rate in children with Down's syndrome. Arch Oral Biol, 51(1), 2006, 23-28.

[38]. Areias C, Sampaio-Maia B, Macho V, Leal I, Melo P, de Andrade C. Does the chemistry in the saliva of down syndrome children explain their low caries prevalence? Eur J Paediatr Dent, 14(1), 2013, 23-26.

[39]. Chaushu S, Becker A, Chaushu G, Shapira J. Stimulated parotid salivary flow rate in patients with Down syndrome. Spec Care Dentist, 22(1), 2002, 41-44. 
[40]. Biology O, Siqueira WLJ, Nicolau J. Stimulated whole saliva components in children with Down syndrome. Spec Care Dentist, 22(6), 2002, 226-230.

[41]. Fiske J, Shafik HH. Down's syndrome and oral care. Dent Update, 28(3), 2001, 148-156.

[42]. Okamoto T, Shibata M, Tsuboi S, et al. Remineralization of primary tooth enamel from individuals with Down syndrome. J Dent Child (Chic), 78(1), 2011, 43-48.

[43]. Buckley S. Teeth grinding. Down Syndr Res Pract, 12(1), 2007, 16-16.

[44]. Anders PL, Davis EL. Oral health of patients with intellectual disabilities: A systematic review. Spec Care Dent, 30(3), 2010, 110-117.

[45]. Seagriff-Curtin P, Pugliese S, Romer M. Dental considerations for individuals with Down syndrome. N Y State Dent J, 72(2), 2006, 33-35.

[46]. Pilcher ES. Treating the patient with Down syndrome. J Contemp Dent Pract, 2(4), 2001, 58-62.

[47]. Shyama M, Al-Mutawa SA, Honkala S, Honkala E. Supervised tooth brushing and oral health education program in Kuwait for children and young adults with Down syndrome. Spec Care Dentist, 23(3), 2003, 94-99. 